\title{
EOSINOPHILIC GRANULOMA OF BONE
}

\author{
Case Record and Short Review of Literature
}

By M. Mistry, M.S., F.R.C.S.

Ex-Surgical Registrar, St. Andrew's Hospital, Bow; Surgical Registrar, The Royal London

Homoeopathic Hospital, London

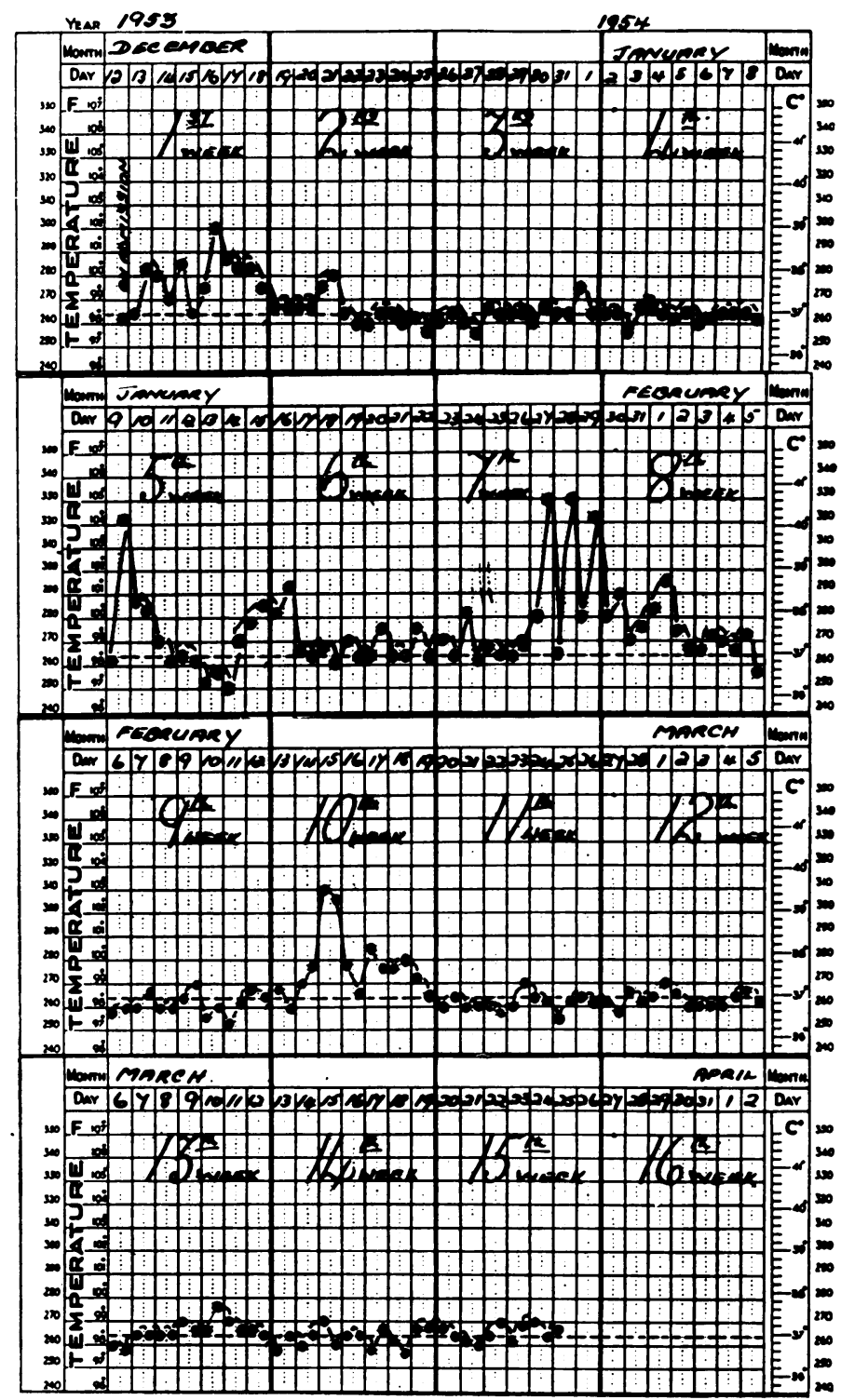

PLATE I.-Temperature chart of the patient showing elevation of temperature in first, fifth, seventh and tenth weeks. 
Eosinophilic granuloma of bone appears to have been first described by Smith (1865), who 'considered that the lesion of the skull in his patient was a dried-up abscess. Several cases by other authors were described later, but the real awakening of interest occurred in 1935 on the publication of a paper on 'Skeletal Lipoid Granulomatosis' in the British Fournal of Surgery by Sir John Frazer. He first described the condition, - now called eosinophilic granuloma, as an early phase of a granulomatous lesion. Otani and Ehrlich (1940) called it the solitary granuloma of the bone, and in the same year Jaffe and Lichtenstein described the same lesion as an eosinophilic granuloma. At that time no one connected this condition with generalized lipoid granulomatosis. However, it soon became evident that the lesion was not always a solitary one. Green and Farber (1942) showed that eosinophilic granuloma was frequently associated with the Hand-SchüllerChristian syndrome and represented, as Sir John Frazer had observed in 1935, as the earliest lesion of the disease.

Granulomatous lesions affecting the reticuloendothelial system produce a group of disorders which are now classified as follows:

\section{Letterer-Siwe disease.}

II. Hand-Schüller-Christian disease.

III. Eosinophilic granuloma.

Jaffe and Lichtenstein (1944) believe that the above three conditions are different clinical expressions of the same basic disorder. Siwe (1949) is unwilling to be as definite as Jaffe and Lichtenstein, but admits that they are all diseases of the reticulo-endothelial system. Siwe further believes that eosinophilic granuloma is a localized condition confined to the skeletal system, while Letterer-Siwe disease is a systemic disease affecting the visceral and skeletal systems, Hand-SchüllerChristian disorder assuming an intermediate position.

The following case is an example of reticuloendothelial granuloma which presented as acute osteomyelitis.

\section{Case Record}

R.P., a female infant of 15 months, was admitted on December 12, 1953, with inability to use the right lower limb.

Examination. Thin, pale-looking child, with sunken eyes and having a small stye on the left lower eyelid. The right lower limb was immobile and externally rotated. There was marked tenderness just above the right greater trochanter.

A provisional diagnosis of acute osteomyelitis was made and supported by:

(I) White blood cell count of 15,000 c.mm.:
Polymorphs, $75 \%$; lymphocytes, $22 \%$; monocytes, $3 \%$.

(2) X-ray plate: Plate I shows a rarefied area in the right ilium just above the joint.

At Operation. The upper part of the hip was exposed through a curved Smith-Petersen incision. On separating the muscles no pus was found and the bony defect exposed. Through this defect a finger could be introduced right into the pelvis. A little dark necrotic material that came out of the cavity was sent for examination. The wound was closed, and the cavity drained.

Post-operative Treatment. Consisted of 250,000 units of procaine penicillin intramuscularly twice a day and 100,000 units through the tube three times a day.

Progress of the Case. For eight days after operation the child ran a fever which gradually settled down. Sudden rises in temperature in fifth, seventh and tenth weeks (Plate I) coincided with chest infections, which were treated.

On December 18 , that is six days after operation, a swelling about the size of a shilling appeared over the right frontal region. This swelling was soft and underneath it an irregular bony defect was felt. X-ray plates were taken which show

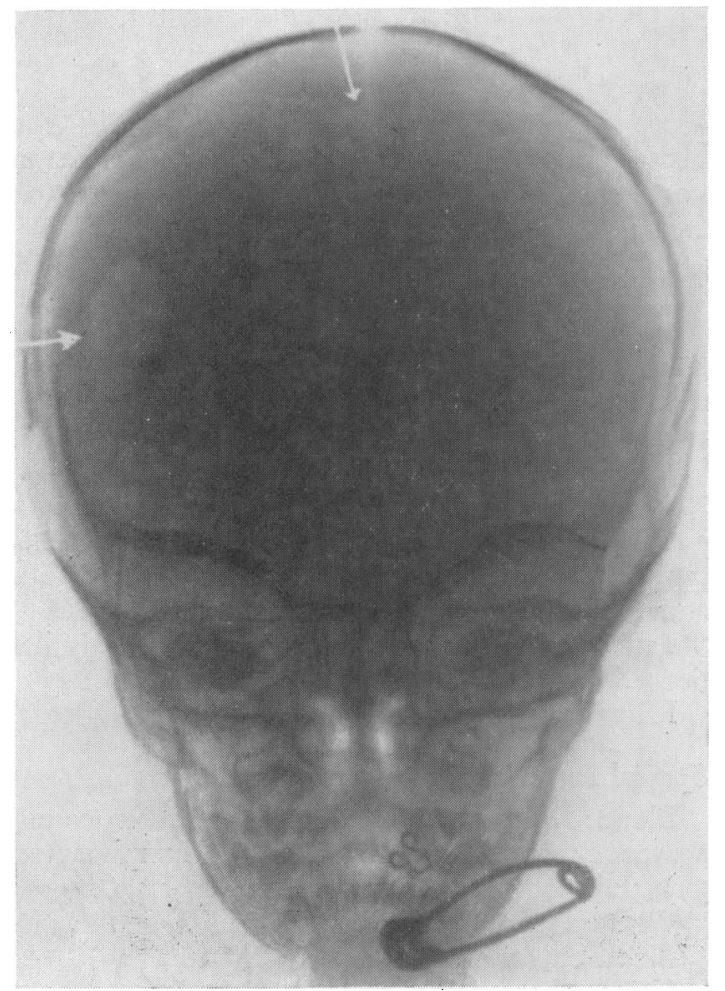

Plate II.-X-ray of skull showing areas of rarefaction. 


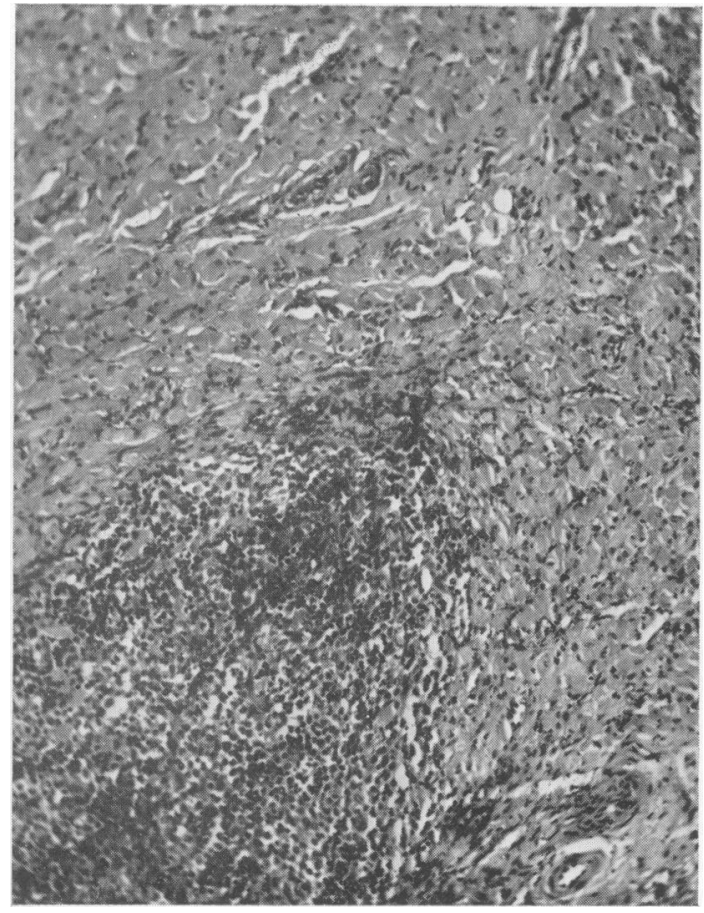

Plate III.-Low power microscopic picture showing muscle tissue infiltrated with eosinophils.

(Plate II) clear (geographical) defects in the frontal and parietal regions. The whole skeleton was then $\mathrm{X}$-rayed and found to be normal at that time.

On January 24 , that is 42 days after admission, the sister of the ward whilst changing the clothes noted an angular deformity of the spine. There was no tenderness over the deformity. An X-ray now showed complete collapse of the body of II th thoracic vertebra.

Microscopic Section Report. (Plates III and IV.) - There is a large amount of necrotic tissue with a diffuse overgrowth of cells of reticulo-endothelial type. There is a heavy infiltration with eosinophils and to a lesser extent by lymphocytes. A bit of the muscle also showed the infiltration by similar tissue.'

Microscopic diagnosis: Eosinophilic granuloma.

\section{Special Investigations}

Blood: $\mathrm{Hb}, 83 \%$. White blood cell count, I 5,500 c.mm.: Polymorphs, $37 \%$; lymphocytes, $59 \%$; monocytes, $2.5 \%$; eosinophils, $1.5 \%$.

Wassermann and Kahn reactions negative.

Blood cholesterol, I $54 \mathrm{mg} . \%$.

Urine showed no abnormality of type and constitutents.



Plate IV.-Same as Plate III under high power. Arrows indicate eosinophils.

Swab report from cavity in bone: Sterile, no growth on Lowenstein's medium.

Swab from stye: Staphylococcus aureus.

Once a definite diagnosis of eosinophilic granuloma was made all the antibiotics were stopped and the child treated with iron, cod-liver oil and vitamin C. For the back a light jacket, reinforced with whale bones, was given.

Further Progress. The child has been followed now for a period of one year and during this period she has been gaining weight and looking much better than she previously did. The swelling over the skull has disappeared, but the angular deformity of the spine is still present, for which she is still wearing a light jacket. New X-ray plates show complete healing of the defects and it was specially noted that the defect in the pelvis which was scraped healed much more quickly than others.

\section{Discussion}

The initial diagnosis of acute osteomyelitis in the case reported above was made on the following points: Marked tenderness over the ilium, presence of stye, X-ray picture (Plate V), and the white blood cell count.

Following the histological examination of the 




Plate V.-X-ray showing destruction of the iliac bone.

scraped material only, a definite diagnosis of eosinophilic granuloma was made.

There are certain curious features in this case that need mentioning: Firstly, the preponderance of males suffering from this condition-the child reported here being female. Secondly, the presence of multiple lesions in this case. And, thirdly, the quicker healing of the lesion in the pelvis treated by surgery.

\section{Incidence, Age and Sex}

Eosinophilic granuloma of bone is a rare condition and Hill, reviewing the whole literature in 1949, found only 72 cases which were acceptable and added one of his own. Since then several other cases have been reported in the British and foreign publications.

This condition has been noted especially in children, but many cases have been recorded in older age-groups.

Dundon et al. (1946) have reported a preponderance of males to the extent of five males to one female.

\section{Etiology}

Etiology is still obscure, but several views have been expressed and they are briefly:
(I) Hand (1893) thought that it was an atypical tuberculosis. There is no microscopical or pathological evidence to say that this view is correct.

(2) Farber and Green (1942) believe that it is due to an infectious agent more likely to be a virus. Attempts to transmit the disease in animals have failed.

(3) Certain authorities like Robb-Smith (1948) regard the above conditions as a secondary lipoidosis due to some disturbance in lipoid metabolism.

\section{Pathology}

The pathology of eosinophilic granuloma of the bone has been described in great detail by Green and Farber (1942) and by Jaffe and Lichtenstein (1940, 1946). The histological appearance of the lesion is characteristic. Masses of eosinophil leucocytes are found in granulomatous lesions composed of solid sheets of histiocytes. There has been considerable discussion concerning the part played by the eosinophils. Eosinophils are, however, less conspicuous in the acute form of the disease. The production of eosinophils in the circulation is debatable, in certain cases there is marked eosinophilia, in others there is none. The reason why eosinophilia occurs is not definitely known, but two views put forward are:

(a) Response of the organism to an infectious agent.

(b) Response to tissue destruction caused by the granulomatous lesion.

Engelbreth-Holm et al. (1942) believe that various histological stages occur in the progress of the lesion towards healing. The stages are as follows:

(I) Hyperplastic proliferative stage.

(2) Granulomatous phase.

(3) Xanthomatous phase.

(4) Healing phase.

\section{Clinical Features}

The important clinical manifestations have been presented in the case reported, but there are certain rare manifestations which are summarized below:

(I) Generalized lymphadenopathy without splenic enlargement has been reported but is not common.

(2) Grupe and Orban (1950) reported an instance of eosinophilic granuloma of the gum which represented a proliferation from a bony lesion between the lower bicuspid teeth.

(3) Wallgren (1940) noted in his case an earlier eruption of teeth.

(4) Eosinophilic granuloma is found more frequently as a single lesion, but more rarely several 
bones may be involved as in the case reported here.

(5) Membrane bones are often involved, but sometimes others may be involved.

\section{Investigations}

$\mathrm{X}$-ray pictures: Radiological investigation is essential. The lesions in the skull, ribs, pelvis, vertebrae, and long bones have characteristic appearances common to all types of reticuloendothelial diseases. Defects in the skull are more clear cut than those elsewhere (Imler, 1946).

Blood picture: (a) Anaemia does occur, it may be progressive and is due to replacement of haemopoietic tissue by the granulomatous lesions.

(b) Eosinophilia: May occur or it may be absent. Usually a moderate degree is present.

Blood cholesterol is frequently normal.

Alkaline phosphatase is sometimes raised.

Biopsy: Diagnosis can be made definitely only by this procedure.

\section{Complications}

(I) Pathological fractures: Sometimes it is the first manifestation of the disease.

(2) Severe progressive anaemia.

(3) Intercurrent chest infections: Quite common as seen in the case reported.

\section{Prognosis}

Eosinophilic granuloma is the least severe of this group of diseases. Patients rarely succumb unless some intercurrent infections supervene, or anaemia is neglected. Letterer-Siwe disease is invariably fatal, and Hand-Schüller-Christian disease once again holding an intermediate position is fatal in 30 per cent. of cases (Sosman, 1930).

\section{Treatment}

There are several methods of treatment and each has its advocates. Spontaneous resolution does occur in this condition, as shown in the case presented, and this leads to the discussion of whether it is justifiable to recommend any other treatment than the conservative regime given below.

\section{Conservative Treatment}

Eosinophilic granuloma may undergo a spontaneous resolution as suggested by Raaf (1945), Burrows (1950) and others. Hence the treatment recommended is a nutritious diet of high protein, low fat and high carbohydrate (Sosman, 1932), with special attention to vitamins and iron.

Anaemia, if it is progressive, may need transfusions. Intercurrent chest infections when they occur need proper treatment.

\section{Surgical Curettage}

Hill (1949) suggested curettage as a method of cure. This procedure is very helpful in solitary lesions and in lesions where it can be applied. There are two very good reasons for advocating this procedure, and they are:

(a) It helps to prove the diagnosis.

(b) Quicker cure, as shown in the pelvis of the case presented.

\section{Deep $X$-ray Therapy}

These granulomatous lesions are radio-sensitive and since deep X-ray therapy has been recommended when multiple lesions are present. The dose recommended is $1,500 \mathrm{r}$ in divided doses over a period of six days.

\section{Cortisone and $A C T H$}

Recently cortisone and ACTH have been recommended for this condition, but the value is debatable. Experimentally Rosenthal, Wald and Yager (1950) have shown that these drugs cause $\mathfrak{r}$ decrease in eosinophils in the circulating blood, but there is no change in the eosinophil count in the bone marrow.

\section{Summary}

A new case of eosinophilic granuloma which presented as a case of acute osteomyelitis is described above with a review of this rare condition from the literature.

\section{Acknowledgments}

It is a great pleasure to express my gratitude to Mr. E. T. Bailey, F.R.C.S., for the permission to publish this case and for the helpful guidance I have received from him. My thanks are also due to Dr. Steingold for microscopic sections and other pathological investigations.

\section{BIBLIOGRAPHY}

BURROWS, H. J. (1950), 'Modern Trends in Orthopaedics', edited by Sir Henry Platt, p. 408.

CAHN, L. (1951), Ann. roy. Coll. Surg. Engl., 2, 131.

CLAIREAUX, A., and LEWIS, I. (1950), Arch. Dis. Childh.

DUNDó3.

(1946), Radiology, 47, 433. TEILUM, G., and CHRISTENSEN, E. (1944), Acta med. scand., 118, 292.

FRAZER, SIR JOHN (1935), Brit. ${ }^{292 .}$. Surg., $22,88$.

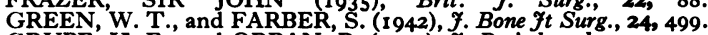
GRUPE, H. E., and ORBAN, B. (1950), $\mathcal{F}$. Periodontol., $21,19$. HAND, A. (1893), Arch. Pediat., 10, 673.

HILL, R. M. (1949), Brit. . Surg., 145, 69

IMLER, A. E. (1946), Amer. F. Roentgenol., 56, 343.

JAFFE, H. L., and LICHTENSTEIN, J. (1940), Amer. F. Path., 16, 595.
JAFFE, H. L., and LICHTENSTEIN, J. (1944), Arch. Path., LYAL, 99. A. (1952), Glas. med. F., 33, 404.

OTANI, S., and EHRLICH, J. Ċ. (1940), Amer. F. Path., 16, 478. RAAF, J. (1945), West. $\mathcal{F}$. Surg., 53, 1 .

ROBB-SMITH,' A. H. 'T. (1948), ' 'British Surgical Practice', ROSENT'HA P. ${ }^{432 .}$. L., WALD, N., and YAGER, A. (1950), Proc. Soc. exp. Biol. (N.Y.), 75, 740.

SIWE, S. A. (1949), 'Advances in Paediatrics', Vol. 4, p. 117.

SMITH, T. (1865), Trans. path. Soc. Lond., 16, 224.

SOSMAN, M. C. (1930), Amer. $\mathcal{F}$. Roentgenol., $23,581$.

SOSMAN, M. C. (1932), Ұ. Amer. med. Ass., 98, 110.

WALLGREN, A. (1940), Amer. $\mathcal{F}$. Dis. Child., 60, 47 1. 